\title{
EFFECT OF HERBAL TOOTHPASTE CONTAINING NEEM LEAVES EXTRACT (AZADIRACHTA INDICA) AGAINST GINGIVITIS: A CLINICAL STUDY
}

\author{
AMELIA PRISCILLA SUGIARTA, ROBERT LESSANG*, NATALINA
}

Department of Periodontology, Faculty of Dentistry, Universitas Indonesia, Jakarta, Indonesia. Email: robertlessang@gmail.com Received 28 September 2018, Revised and Accepted 23 February 2019

\section{ABSTRACT}

Objective: Neem leaves are known to have antibacterial, anti-inflammatory, antifungal, antiseptic, antitumor, antihyperglycemic, antiulcer, and antiviral effects. In addition, they can reduce the counts of plaque-forming bacteria in the oral cavity. This study aimed to evaluate the effect of an herbal toothpaste containing neem leaves extract against gingivitis.

Methods: A total of 40 subjects were divided into two groups ( $\mathrm{n}=20$ each): Experimental and control. Those in the test group were instructed to brush their teeth twice a day for 7 days with neem leaves extract toothpaste, whereas the control group subjects were asked to continue with the non-herbal paste they used for tooth brushing. Plaque index (PI) and papillary bleeding index (PBI) were measured on day 0 and day 7 .

Results: Significant reductions in PI and PBI were noted between the test and control groups.

Conclusion: The findings of this clinical study provide evidence that neem leaf extracts are effective in reducing gingivitis.

Keywords: Neem leaves extract, Gingivitis, Plaque index, Papillary bleeding index.

(C) 2019 The Authors. Published by Innovare Academic Sciences Pvt Ltd. This is an open access article under the CC BY license (http://creativecommons. org/licenses/by/4. 0/) DOI: http://dx.doi.org/10.22159/ijap.2019.v11s1.AR173

\section{INTRODUCTION}

Periodontal disease, especially gingivitis and periodontitis, is one of the most common diseases of the oral cavity. The average number of patients requiring periodontal treatment had reached 72,223 as recorded in the Indonesian Health Data Profile in 2011 [1].

Gingivitis is the result of interactions between inflammatory cells and microorganisms found in dental plaque and gums. In gingivitis, the gingival epithelium remains attached to the tooth in its original position. If the condition is left untreated, the inflammatory process will continue to progress and involve the gingiva and periodontium, leading to loss of periodontal attachment and resulting in periodontitis [2]

The main etiology of gingivitis is bacterial plaque that accumulates on the tooth and within gingival margins. Gingivitis is also influenced by several factors that are divided into two main categories, local factors and systemic factors. The local factors consist of dental plaque, calculus, dental anatomy, and overhanging restorations, whereas the systemic factors include age, sex, hormones, nutritional status, blood diseases, and the use of certain drugs. In general, a combination of these factors is found in patients with gingivitis [3].

Good nutrition, dental and oral health education, and motivation for the maintenance of oral hygiene are some of the ways by which the occurrence of gingivitis can be prevented. Brushing the teeth and using dental floss as well as mouthwash will help maintain oral hygiene [4].

Brushing is one of the simplest attempts at controlling plaque and the first step in controlling caries and periodontal disease. To control plaque, active components that contain natural or synthetic ingredients are added to the toothpaste [5]. However, some chemicals in toothpastes, such as triclosan, exert adverse effects on the oral cavity and the body. Triclosan is reported to be able to react with water and form chloroform, which, if inhaled in large quantities, leads to liver diseases and cancer [6]. In addition, triclosan has been shown to have no significant antibacterial abilities [7]. Therefore, toothpastes containing natural or herbal ingredients are considered to be more effective in killing bacteria and safer for use from a health point of view [8].

Neem or Azadirachta indica is a plant that has been used for medicinal purposes in India for $>4000$ years. This plant is also often called as the Indian lilac and is a member of the mahogany family. Neem has been listed as one of the plants used in the Indian system of natural treatment, the Ayurveda. The leaves, stems, flowers, fruits, seeds, and oils of this plant have been used to cure various conditions such as wounds, cough, fever, loss of appetite, skin diseases, and diabetes mellitus. Neem leaves have antibacterial, anti-inflammatory, antifungal, antiseptic, antitumor, antihyperglycemic, antiulcer, and antiviral effects [9]. In addition, neem leaves have the ability to reduce the number of Streptococcus mutans, a common plaque-forming bacteria found in the oral cavity [10].

The use of neem plants as herbal medicine is less common in Indonesia. The number of studies on the use of neem leaves in Indonesia is few, which may be due to the limited findings that support the use of this plant as an herbal medicine [11]. The present study aimed to evaluate the effect of an herbal toothpaste containing neem leaves extract on gingivitis. We hope that the findings of this study will help in spreading awareness among the Indonesian population about the benefits of neem plants, especially as an antibacterial agent that can prevent the occurrence of dental and oral diseases.

\section{METHODS}

This clinical experimental study comprised 40 subjects divided into two groups, test and control $(\mathrm{n}=20$ each). All subjects were instructed to brush their teeth twice daily for 7 days. The test group was provided with an herbal toothpaste containing neem leaves extract, whereas the control group was instructed to brush their teeth with the non-herbal toothpaste they used before this study. 
On day 0 , plaque index (PI) and papillary bleeding index (PBI) were measured in all subjects by tracing the gingival sulcus with a probe on the buccal and lingual surfaces in a mesiodistal direction. On the $7^{\text {th }}$ day, the PI and PBI were measured again, and the differences in measurements between the two time points were calculated.

The data in the current study were analyzed using IBM-SPSS. Shapiro-Wilk normality test was used to analyze the PI and PBI results. Significant differences in PI and PBI scores within groups before and after treatment and between the two groups after treatment were determined using paired t-test and independent t-test, respectively. The significance level was set at $0.05(\mathrm{p}=0.05)$ and the confidence level at $95 \%(a=0.05)$.

\section{RESULTS}

The mean values of the PI (Fig. 1) and PBI (Fig. 2) scores were decreased after treatment in the test and control groups. Significant differences in PI and PBI scores were observed in the test group before and after treatment, whereas in the control group, no significant differences in scores were noted before and after treatment $(p<0.05)$. Moreover, significant differences in PI and PBI scores between the test and the control groups were found after treatment $(\mathrm{p}<0.05)$

\section{DISCUSSION}

In the present study, the effects of an herbal toothpaste containing neem leaves extract on gingivitis were determined by measuring the differences in PI and PBI between a test and a control group of subjects. Paired t-test revealed a significant decrease in PI and PBI scores in the test group after the use of the herbal toothpaste, thus indicating the effectiveness of neem leaves against gingivitis. Decrease in plaque scores may have been caused by the action of Azadirachta in the neem leaf extract, a known antibacterial agent [12]

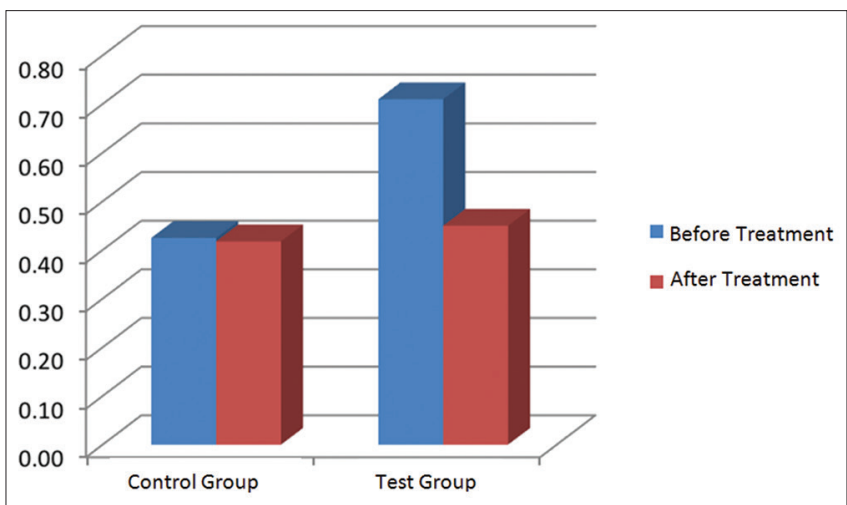

Fig. 1: Comparison diagram of plaque indeks score before and after use of toothpaste in control and test group

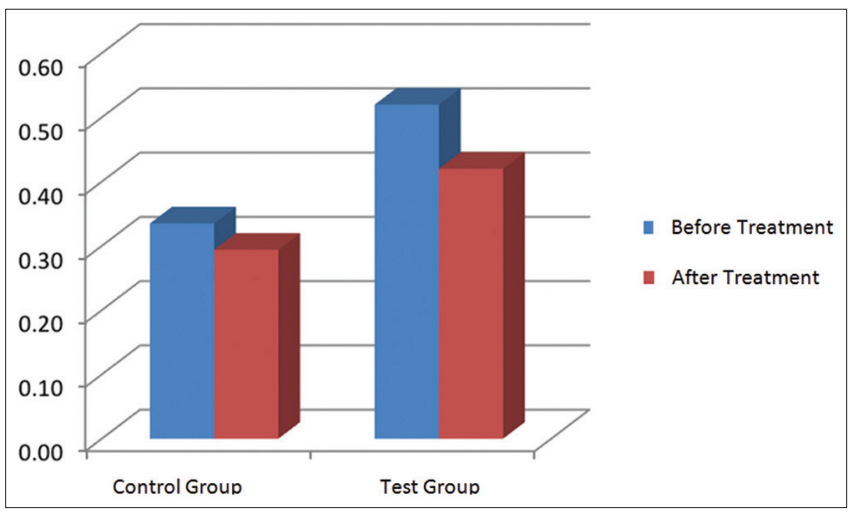

Fig. 2: Comparison diagram of pbi score before and after use of toothpaste in control and test group
The decrease in PI and PBI scores in the control group, though insignificant, may be due to the awareness among subjects to maintain oral hygiene after they were exposed with gingivitis appearance and sign or due to the fact that their oral health status was being monitored regularly. In addition, regular brushing instructions can decrease plaque accumulation and are one of the most effective dental cleaning methods for gingivitis patients $[13,14]$. Increased PI and PBI scores may be affected by the non-compliance of the subject to instructions given during the study. Variations in the increase or decrease of PI and PBI scores may also be affected by the type of toothpaste and toothbrush used by the subject every day. Nearly $80 \%$ of the subjects used toothpastes that are commonly used for the care and prevention of dental caries. $20 \%$ of subjects were found to use toothpastes prescribed for the treatment of sensitive teeth. Moreover, $85 \%$ of the subjects used a toothbrush with a tapered brush head, $20 \%$ used toothbrushes with soft bristles, and 15\% used standard American Dental Association toothbrushes. Different types of toothpastes and toothbrushes have different functions and abilities in disposing dental plaque, thus accounting for the variations in PI and PBI scores in the control group.

Unpaired $t$-tests showed significant differences in PI and PBI scores between the control and test groups. The previous studies have determined the effects of neem leaf mouthwashes, but not toothpastes, against gingival inflammation [10]. In the study by Botelho et al., the effect of neem leaf mouthwash was compared with that of $0.12 \%$ chlorhexidine in 54 subjects with chronic gingivitis [10]. PI, gingival index, gingival bleeding index, and $S$. mutans counts in saliva were measured before and after the $1^{\text {st }}$ and $4^{\text {th }}$ week of treatment. No significant differences between the two groups of subjects were noted. Furthermore, a dramatic decrease in the number of cariogenic bacteria was noted in both groups, but the difference between the two was not statistically significant [10]. Similarly, Chatterjee et al. reported no significant differences gingival bleeding and PI between subjects using neem leaf extract $(0.19 \%)$ and those using chlorhexidine $(0.2 \%)$ mouthwashes [15]. However, both studies stated that neem leaf extract had no side effects, whereas chlorhexidine was associated with an unpleasant taste in the mouth and tooth staining [15]. This suggests that the results of these two studies do not correspond with those of existing journals. However, studies are still limited by the use of mouthwash, not with the use of toothpaste as conducted by researchers.

Given the significant decrease in PI and PBI scores in the group using neem leaf extracts, this study provides evidence that tooth brushing with neem leaf extracts can be an effective alternative for the reduction of gingival inflammation when compared with non-herbal toothpastes. This is due to the ability of neem plants to inhibit bacterial colonization of streptococci and plaque formation [16].

The antibacterial properties of neem plants have been demonstrated by Bhat et al., wherein antibacterial solutions containing neem had the highest effectiveness in reducing the number of $S$. mutans when compared with turmeric, chlorhexidine, and cetylpyridinium chloride [17]. However, further studies evaluating the effectiveness of herbal toothpastes containing neem leaf extracts in larger samples with severe gingival inflammation over a longer time frame are warranted.

\section{CONCLUSION}

On the basis of the results of this study, it can be concluded that tooth brushing with an herbal toothpaste containing neem leaf extracts can reduce gingival inflammation and both PI and PBI scores more effectively when compared with non-herbal toothpastes.

\section{CONFLICTS OF INTEREST}

Declared none.

\section{REFERENCES}

1. Ministry of Health, Republic of Indonesia. Indonesia Health Profile. Jakarta: Ministry of Health, Republic of Indonesia; 2011. 
2. John NM. Classification of disease and conditions affecting the periodontium. In: Newman MG, Takei HH, Carranza FA, editors. Clinical Periodontology. $10^{\text {th }}$ ed. Philadelphia, PA: W.B. Saunders Co.; 2006. p. 100-4.

3. Allen DL, McFall WT, Hunter GC. Periodontics for Dental Hygienist. $2^{\text {nd }}$ ed. Great Britain: Lea and Febiger; 1986. p. 60-86.

4. Grant DA, Stern IB, Everett FG. Orban's Periodontics a ConceptTheory and Practice. London: C.V Mosby Co.; 1972. p. 28-35.

5. Pratiwi R. Differences in the inhibitory power of Streptococcus mutans from herbal toothpaste. Majalah Kedokt Gigi 2005;38:64-7.

6. Davies R, Scully C, Preston AJ. Dentifrices-an update. Med Oral Patol Oral Cir Bucal 2010;15:e976-82.

7. Furgang D, Sreenivasan PK, Zhang YP, Fine DH, Cummins D. The effects of a new therapeutic triclosan/copolymer/sodium-fluoride dentifrice on oral bacteria, including odorigenic species. Compend Contin Educ Dent 2003;24:14-9.

8. Tsyarini E, Rusmana D, Widya. Comparison of the Effectiveness of Herbal Toothpaste and Nonherbal Toothpaste in Inhibiting the Growth of Staphylococcus aureus, Streptococcus $\beta$-hemoliticus and Candida albicans in vitro. [In Indonesia]. [Thesis]. Faculty of Dentistry, Universitas Maranatha; 2003. p. 1-27.

9. Girish K, Shankara SB. Neem-a green treasure. Electron J Biol 2008;4:102-11

10. Botelho MA, dos Santos RA, Martins JG, Carvalho CO, Paz MC,
Azenha C, et al. Efficacy of a mouthrinse based on leaves of the neem tree (Azadirachta indica) in the treatment of patients with chronic gingivitis: A double blind, randomized, controlled trial. J Med Plant Res 2008;2:341-6.

11. Masluhiya S. Pemanfaatan Daun Mimba (Azadirachta indica); 2011. Available from: http://www.jamu.biologi.ub.ac.id/?page_id=397.

12. Saradhajyoti K, Subbarao B. Antibacterial potential of extract of the leaves of Azadirachta indica Linn. Not Sci Biol 2011;3:65-9.

13. Carranza FA, Rapley JW. Clinical features of gingivitis. In: Carranza FA, Newman MG, Takei HH, editors. Carranza's Clinical Periodontology. $9^{\text {th }}$ ed. Toronto: WB. Saunders Co.; 2002. p. 269-77.

14. Markou E, Eleana B, Lazaros T, Antonios K. The influence of sex steroid hormones on gingiva of women. Open Dent J 2009;3:114-9.

15. Chatterjee A, Saluja M, Singh N, Kandwal A. To evaluate the antigingivitis and antipalque effect of an Azadirachta indica (Neem) mouthrinse on plaque induced gingivitis: A double-blind, randomized, controlled trial. J Indian Soc Periodontol 2011;15:398-401.

16. Wolinsky LE, Mania S, Nachnani S, Ling S. The inhibiting effect of aqueous Azadirachta indica (Neem) extract upon bacterial properties influencing in vitro plaque formation. J Dent Res 1996;75:816-22.

17. Bhat PK, Badiyani BK, Sarkar S, Chengappa S, Bhaskar NN. Effectiveness of antimicrobial solutions on Streptococcus mutans in used toothbrushes. World J Dent 2012;3:6-10. 